\title{
ANALISIS KEMAMPUAN TEKNIK DASAR PASSING, DRIBBLING, DAN SHOOTING PADA PEMAIN SEPAK BOLA SSB PUTRA U 10-12 TAHUN DI KABUPATEN KAUR
}

\author{
Dadang Sulistio \\ Program Studi Pendidikan Jasmani FKIP Universitas Bengkulu \\ Email : dadangpepe98@.gmail.com \\ Sugiyanto \\ Universitas Bengkulu \\ Defliyanto \\ Universitas Bengkulu
}

\begin{abstract}
Abstrak
Penelitian ini bertujuan untuk mengetahui tingkat dari kemampuan teknik dasar pemain sepak bola SSB Putra U 10-12 Tahun di Kabupaten Kaur. Jenis penelitian ini adalah diskriptif kualitatif, dimana hanya menganalisa kemampuan teknik dasar Passing, Dribbling, dan Shooting. Sampel dari penelitian ini berjumlah sebanyak 36 orang. Berdasarkan hasil analisis data bahwa kemampuan Passing adalah 30 orang (83,3\%) tergolong kedalam kategori baik, dan 6 orang $(16,7 \%)$ dalam kategori sedang dari total peserta tes sebanyak 36 orang, sehingga teknik dasar

Passing dikategorikan baik. Kemampuan Dribbling sebanyak 30 orang (83,3\%) dalam kategori sedang, dan 6 orang $(16,7 \%)$ dalam kategori kurang dari total 36 orang, sehingga teknik dasar Dribling dikategorikan sedang. Dan kemampuan Shooting sebanyak 2 orang $(5,6 \%)$ dalam kategori kurang, dan 34 orang $(94,4 \%)$ dalam kategori kurang sekali sehingga kemampuan Shooting dapat dikategorikan kurang sekali.
\end{abstract}

Kata Kunci : Kemampuan, Teknik Dasar, Sepak Bola

\begin{abstract}
This research aims to know the level of basic technical in SSB Male Soccer Players U 10-12 Years in Kaur Regency. This type of research is descriptive qualitative, which only analyzes the ability of basic techniques of Passing, Dribbling, and Shooting. The sample of this research amounted to 36 people. Based on the results of data analysis that the Passing ability is 30 people (83.3\%) belonging to the good category, and 6 people (16.7\%) in the medium category of the total test participants as many as 36 people, so the basic technique of Passing is categorized as good. Dribbling ability is 30 people (83.3\%) in the moderate category, and 6 people (16.7\%) in the less category, out of a total of 36 people, so the basic Dribling technique is categorized as moderate. And Shooting ability as many as 2 people (5.6\%) in the less category, and 34 people (94.4\%) in the category less so that Shooting ability can be categorized less.
\end{abstract}

Keywords: Ability, Technique, Bassic Football 


\section{PENDAHULUAN}

Olahraga adalah serangkaian gerak raga yang teratur dan terencana yang dilakukan orang untuk mencapai maksud dan tujuan tertentu (Y.S Santosa Giriwijoyo, 2005 : 10). Berdsarkan tujuan yang hendak dicapai, maka olahraga dibagi menjadi : 1 . Olahraga prestasi-tekanannya pada pencapaian prestasi, 2. Olahraga rekreasitekanannya pada rekreasi, 3. Olahraga kesehatan - tekanannya pada pencapaian kesehatan, 4. Olahraga pendidikantekanannya pada pencapaian tujuan pendidikan.

Olahraga merupakan hal yang sudah menjadi kegiatan keseharian bagi manusia, olahraga banyak digemari oleh manusia baik sebagai pelaku ataupun hanya penggemar saja. Olahraga dapat membantu perkembangan badan dan perkembangan sikap, mampu mengatasi ketegangan yang dialami serta dapat memberikan nilai-nilai kemanusiaan yang sangat berharga untuk sesamanya.

Indra Sjafri,(2017:1) Sepak bola adalah Olahraga permainan menggunakan bola yang dimainkan oleh 2 (dua) tim. Umumnya masing masing tim terdiri dari sebelas (11) orang pemain yang terdiri dari seorang penjaga gawang, 2-4 orang pemain bertahan, 2-4 orang pemain tengah, 1-3 orang pemain menyerang. Penjaga gawang merupakan satu satunya pemain yang dipebolehkan memegang boleh demi mencegah bola serangan dari tim lawan memasuki gawang yang dijaganya. Sedangkan menurut Andra Akbar, (2013:1) mengemukakan bahwa Sepak bola adalah suatu permainan beregu yang terdiri dari dua tim yang berjumlah sebelas orang (11) dengan salah satu sebagai penjaga gawang, dengan waktu 2x45 menit dan waktu istirahat selama 15 menit, dan dipimpin oleh seorang wasit ditengah lapangan, dua hakim garis, dan official lainnya. Dimana dalam permainan ini pemain dituntut haruslah memiliki teknik, taktik, kelincahan, kekuatan fisik, dan kebersamaan dalam sebuah tim dengan tujuan untuk memasukan bola kegawang lawan dan menjaga daerah pertahanan dan gawang timnya sendiri dengan mengikuti peraturan yang telah ditetapkan FIFA.

Sepak bola merupakan cabang olahraga yang legendaris, dan termasuk salah satu cabang olahraga yang banyak. penggemarnya . sepak bola merupakan gaya permainan cepat, dimana pemain dituntut memiliki keterampilan, teknik dan taktik. Badan yang menaungi segala sesuatu tentang sepak bola Internasional di sebut FIFA yang bermarkas dikota Zurich, SWISS. Di Indonesia badan yang menangani sepak bola disebut PSSI yang berdiri pada tanggal 19 april 1930.

Dalam permainan sepak bola kemampuan teknik sangat penting untuk dikuasai dan dipelajari oleh pemain. Robert Kogger (2007:13) mengemukakan: keterampilan bersepak bola yang sesungguhnya, yang diperlukan disetiap pemain sebelum mereka benar-benar bertanding melawan tim lain. Teknik-teknik permainan ini menunjukan cara pembawaan diri didalam pertandingan yang sesungguhnya.

Dilihat dari kutipan diatas dapat disimpulkan bahwa olahraga sepak bola merupakan suatu cabang olahraga yang dilandasi dengan kemampuan individu maupun tim yang mempunyai aktivitas gerak dan teknik (keterampilan) dan ditunjang dengan kemampuan fisik yang bagus saat bermain serta dengan adanya susunan taktik dalam tim yang akan 
mempermudah untuk melakukan pola permainan dalam lapangan.

$$
\text { Sucipto dkk,(2000:7) }
$$

mengemukakan tujuan dari permainan sepak bola adalah pemain memasukan bola sebanyak-banyaknya kegawang lawannya dan berusaha untuk menjaga gawangnya supaya tidak kemasukan. Karna dalam permainan selama $2 \times 45$ menit akan menentukan hasil dari pertandingan, di mana setiap tim masing masing memiliki tujuan yang sama yaitu untuk memenangkan pertandingan.

Sepak bola merupakan salah satu olahraga permainan yang saat ini sangat populer di masyarakat Indonesia khususnya di Kabupaten Kaur. Perkembangan ini dapat dilihat dengan berdirinya SSB Amura, Persiku dan Serumpun.

Dari uraian diatas dapat disimpulkan bahwa sepak bola merupakan olahraga permainan yang membutuhkan kemampuan penguasaan teknik, taktik, dan mental agar bisa melakukan permainan secara maksimal. Maka dari itu seorang atlit juga dituntut untuk melakukan latihan yang teratur dan disiplin, serta memiliki sikap sportivitas yang tinggi. Indra Sjafri ddk, (2017:6) mengemukakan bahwa permainan sepak bola anak pada dasarnya merupakan bimbingan karakter melalui olahraga permainan. Pelatihan sepak bola anak tidak memaksakan anak untuk dapat mahir dan setara dengan orang dewasa, tapi justru mempersiapkan hal hal dasar yang dapat menjadi bekal landasan anak dalam menerapkan, mempraktikan, dan mengembangkan hal tersebut secara konkret saat perkembangan fisik dan mentalnya telah matang nantinya, untuk itu pelatihan sepak bola anak dikemas dalam bentuk pelatihan dasar yang sesuai dengan kemampuan dan ketertarikan anak dalam mencerna informasi, yaitu dalam melalui bimbingan. Pelatihan sepak bola anak haruslah berlandaskan keceriaan dalam bermain sepak bola. Sepak bola anak harus menyenangkan, bukan kerja keras, berdasarkan hal itu, FIFA merumuskan filosofi yang harus diemban bagi para pelatih sepak bola anak, agar pelatihan tidak mengakibatkan trauma bagi anak.

Menurut Indra Sjafri dkk, (2017:9) bahwa perlengkapan standar dalam pelatihan sepak bola usia 10-12 tahun ialah

a. Bola

Bola adalah benda bulat berisi udara yang merupakan perlengkapan utama permainan sepak bola, dan ukuran bola untuk pelatihan anak usia 10-12 tahun adalah ukuran 4 dengan tingkat kebundaran yang sempurna.

b. Lapangan

Lapangan adalah tempat untuk melakukan permainansepak bola, dimana lapangan memiliki berbagai ukuran sesuai dengan umur dan ketentuan. Lapangan yang digunakan untuk pelatihan anak usia 10-12 tahun memiliki ukuran panjang 60-75 meter dan lebar 40-46 meter.

c. Gawang

Gawang adalah rintangan berupa dua tiang yang diatasnya diberi mistar dengan ketinggian tertentu, gawang adalah lokasi penentu penambahan skor suatu tim dengan cara memasukan bola kegawang atau gol. Gawang dijaga oleh seorang penjaga gawang yang disebut kiper. Ukuran gawang yang umu adalah $3 \times 1,5$ meter atau $3,5 \times 1,8$ meter. Namun untuk permainan sepak bola anak gawang yang digunakan dengan ukuran 1,8-2,1 m x 3,6-4,8 meter.

d. Cone / Kerucut

Kerucut adalah pancang dari plastik yang digunakan untuk rintangan saat latihan, penggunaan kerucut dimaksudkan untuk melatih kelincahan dalam membawa bola 
dan ketangkasan dalam bermanuver saat menerima hadangan dari pemain lawan.

\section{METODE}

Metode penelitian adalah keseluruhan rencana untuk mendapatkan jawaban atas pernyataan yang sedang dipelajari dan untuk menangani berbagai tantangan terhadap bukti penelitian yang layak. Sesuai dengan judul penelitian "Analisis Kemampuan Teknik Dasar Passing, Dribbling, dan Shooting Pada Pemain Sepak Bola SSB Putra U 10-12 Tahun di Kabupaten Kaur" maka jenis penelitian adalah diskriptif kualitatif. Dimana hanya akan menganalisis teknik passing, dribbling, dan shooting pada SSB di kabupaten Kaur.

Hasil tes akan disajikan dalam bentuk Ashef Novriansyah, (2017:37). Penelitian diskriptif merupakan penelitian yang dilakukan untuk menggambarkan keadaan sebenarnya tentang sebuah variabel, gejala, atau keadaan, bukan untuk menguji hipotesis tertentu.

\section{HASIL DAN PEMBAHASAN}

Penelitian ini terdiri dari deskripsi data, distribusi frekuensi tes kemampuan dasar sepak bola (frekuensi tes passing, dribbling, dan shooting di SSB putra u 10-12 tahun di Kabupaten Kaur. Deskripsi data sesuai dengan hasil temuan factual dilapangan tanpat ada rekayasa. Berdasarkan sampel yang ditentukan dalam penelitian adalah cluster sampling. Berdasarkan hasil data variabel passing, dribbling, dan shooting, ternyata dari 36 pemain yang terdiri dari 3 tim SSB di mana setiap SSB terdiri dari 12 testee yang di teliti dikategorikan dalam $U$ 10-12 tahun di Kabupaten Kaur diperoleh hasil sebagai berikut: 1) SSB Amura Setelah menganalisis pemain dari SSB Amura maka diperoleh hasil analisis sebagai berikut: a) Kemampuan Short Past SSB Amura Dari data yang diperoleh melalui tes dan pengukuran yang dilakukan pada pemain bahwa Skor terbesar yang diperoleh dari 12 pemain SSB Amura dalam melakukan Passing ke dalam gawang adalah 4 skor terendah 2, dengan waktu yang terlama adalah 10,50 dan waktu tercepat adalah 7,16 detik, sebanyak 12 pemain (100\%) dalam katagori baik, dan rata-rata skor yang diperoleh 3,42. Tabel 8 Pengelompokan Skor Short Past.

\begin{tabular}{c|c|c|c} 
No & K T-skore & F Absolut & F Relatif \\
\hline 1 & BS $\geq 124$ & 0 & $0 \%$ \\
\hline 2 & B 104-123 & 12 & $100 \%$ \\
\hline 3 & S 85-103 & 0 & $0 \%$ \\
\hline 4 & K 65-84 & 0 & $0 \%$ \\
\hline 5 & KS $\leq 64$ & 0 & $0 \%$ \\
\hline \multicolumn{2}{c}{ Jumlah } & 12 & $100 \%$
\end{tabular}

b) Kemampuan Dribbling SSB Amura Dari data yang diperoleh melalui tes dan pengukuran yang dilakukan pada pemain bahwa Skor terbesar yang diperoleh dari 12 pemain SSB Amura adalah 18,31 detik dan skor terendah 14,87 detik, sebanyak 12 pemain (100\%) dalam katagori sedang, dan skor rata-rata yang diperoleh adalah 16,35. Tabel 9 Pengelompokan Skor Dribbling

\begin{tabular}{c|c|c|c} 
No & K t-skore & F absolut & F relatif \\
\hline 1 & BS $\geq 66$ & 0 & $0 \%$ \\
\hline 2 & B 55-66 & 0 & $0 \%$ \\
\hline 3 & S 41-52 & 12 & $100 \%$ \\
\hline 4 & K $\leq 40$ & 0 & $0 \%$ \\
\hline \multicolumn{2}{|c|}{ Jumlah } & 12 & $100 \%$
\end{tabular}

c) Kemampuan Shooting SSB Amura Dari data yang diperoleh melalui tes dan pengukuran yang dilakukan pada pemain maka diperoleh data yaitu bahwa Skor terbesar yang diperoleh dari 12 pemain SSB Amura adalah 53 dan skor terendah 30, dengan jumlah 428 dan rata rata 40,17. 
sebanyak 12 pemain (100\%) dalam kategori Kurang Sekali. Tabel 10 Pengelompokan Skor Shooting.

\begin{tabular}{c|c|c|c} 
No & K t-skore & F absolut & F relatif \\
\hline 1 & BS $\geq 67$ & 0 & $0 \%$ \\
\hline 2 & B 55-66 & 0 & $0 \%$ \\
\hline 3 & S 44-54 & 0 & $0 \%$ \\
\hline 4 & K $32-43$ & 0 & $0 \%$ \\
\hline 5 & KS $\leq 31$ & 12 & $100 \%$ \\
\hline \multicolumn{2}{c|}{ Jumlah } & 12 & $100 \%$
\end{tabular}

2) SSB Serumpun: a) Kemampuan Short Past SSB Serumpun dari data yang diperoleh melalui tes dan pengukuran yang dilakukan pada pemain dapat disimpulkan bahwa Skor terbesar yang diperoleh dari 12 pemain SSB Serumpun adalah 4 dan skor terendah 2, dalam waktu terlama adalah 10,64 detik dan skor tercepat adalah 7,70 detik, sebanyak 9 pemain (75\%) dalam katagori baik, sebanyak 3 pemain (25\%) dalam katogori sedang dan rata-rata skor yang diperoleh 2,75. Tabel 11 Pengelompokan Skor Short Past.

\begin{tabular}{c|c|c|c} 
No & K t-skore & F absolut & F relatif \\
\hline 1 & BS $\geq 124$ & 0 & $0 \%$ \\
\hline 2 & B 104-123 & 9 & $75 \%$ \\
\hline 3 & S $85-103$ & 3 & $25 \%$ \\
\hline 4 & K $65-84$ & 0 & $0 \%$ \\
\hline 5 & KS $\leq 64$ & 0 & $0 \%$ \\
\hline \multicolumn{2}{c|}{ Jumlah } & 12 & $100 \%$
\end{tabular}

b) Kemampuan Dribbling SSB Serumpun, dari data yang diperoleh melalui tes dan pengukuran yang dilakukan pada pemain dapat disimpulkan bahwa Skor terbesar yang diperoleh dari 12 pemain SSB Serumpun adalah 19,43 detik dan skor terendah 14,87 detik, sebanyak 4 pemain (33.3\%) dalam kategori kurang dan 8 pemain $(66,67 \%)$ dalam kategori sedang, jumlah skor 203.41 dan rata-rata skor yang diproleh 16,95. Tabel 12 Pengelompokan Skor Dribbling.

\begin{tabular}{c|c|c|c} 
No & K t-skore & F absolut & F relatif \\
\hline 1 & BS $\geq 66$ & 0 & $0 \%$ \\
\hline 2 & B $53-65$ & 0 & $0 \%$ \\
\hline 3 & S 41-52 & 8 & $66.67 \%$ \\
\hline 4 & K $\leq 64$ & 4 & $33.3 \%$ \\
\hline \multicolumn{2}{r|}{ Jumlah } & 12 & $100 \%$
\end{tabular}

c) Kemampuan Shooting SSB Serumpun, dari data yang diperoleh melalui tes dan pengukuran yang dilakukan pada pemain dapat disimpulkan bahwa Skor terbesar yang diperoleh dari 12 pemain SSB Serumpun adalah 53 dan skor terendah 30, sebanyak 1 pemain (8.3\%) dalam katagori kurang dan 11 pemain (91.7\%) dalam kategori kurang sekali, dengan rata-rata skor yang diproleh 40,75. Tabel 13 Pengelompokan Skor Shooting.

\begin{tabular}{c|c|c|c} 
No & K t-skore & F absolut & F relatif \\
\hline 1 & BS $\geq 67$ & 0 & $0 \%$ \\
\hline 2 & B $55-66$ & 0 & $0 \%$ \\
\hline 3 & S $44-54$ & 0 & $0 \%$ \\
\hline 4 & K $32-43$ & 1 & $8.3 \%$ \\
\hline 5 & KS $\leq 31$ & 11 & $91.7 \%$ \\
\hline \multicolumn{2}{r|}{ Jumlah } & 12 & $100 \%$
\end{tabular}

3) SSB Persiku :

a) Kemampuan Short past SSB Persiku, dari data yang diperoleh melalui tes dan pengukuran yang dilakukan pada pemain dapat disimpulkan bahwa Skor terbesar yang diperoleh dari 12 pemain SSB Persiku adalah 4 dan skor terendah 2, sebanyak 3 pemain (25\%) dalam kategori sedang, sebanyak 9 pemain (75\%) dengan 2 kategori baik, dan rata-rata skor yang diperoleh 2,75 dan jumlah 33. Tabel 14 pengelompokan skor Short past. 


\begin{tabular}{c|c|c|c} 
No & K t-skore & F absolut & Frelatif \\
\hline 1 & BS $\geq 67$ & 0 & $0 \%$ \\
\hline 2 & B $55-66$ & 9 & $75 \%$ \\
\hline 3 & S $44-54$ & 3 & $25 \%$ \\
\hline 4 & K $32-43$ & 0 & $0 \%$ \\
\hline 5 & KS $\leq 31$ & 0 & $0 \%$ \\
\hline \multicolumn{2}{r|}{ Jumlah } & 12 & $100 \%$
\end{tabular}

b) Kemampuan Dribbling SSB Persiku, dari data yang diperoleh melalui tes dan pengukuran yang dilakukan pada pemain dapat disimpulkan bahwa Skor terbesar yang diperoleh dari 12 pemain SSB Persiku adalah 19,29 detik dan skor terendah 14,59 detik, sebanyak 2 pemain $(12,7 \%)$ dalam kategori kurang, sebanyak 10 pemain $(83,3 \%)$ dalam kategori sedang dan ratarata yang diperoleh 17,03 dengan jumlah 204,32. Tabel 15 Norma Penilaian Test Dribbling.

\begin{tabular}{c|c|c|c} 
No & K t-skore & F absolut & F relatif \\
\hline 1 & $\mathrm{BS} \geq 67$ & 0 & $0 \%$ \\
\hline 2 & $\mathrm{~B} 53-65$ & 0 & $0 \%$ \\
\hline 3 & $\mathrm{~S} 41-52$ & 10 & $83.3 \%$ \\
\hline 4 & $\mathrm{~K} \leq 40$ & 2 & $12.7 \%$ \\
\hline \multicolumn{2}{r|}{ Jumlah } & 12 & $100 \%$
\end{tabular}

c) Kemampuan Shooting SSB Persiku, dari data yang diperoleh melalui tes dan pengukuran yang dilakukan pada pemain dapat disimpulkan bahwa Skor terbesar yang diperoleh dari 12 pemain SSB Persiku adalah 53 dan skor terendah 30, sebanyak 1 pemain $(8.3 \%)$ dalam katagori Kurang dan 11 pemain $(91.7 \%)$ dalam kategori kurang sekali dengan rata-rata skor yang diperoleh 41,42 dan jumlah skor adalah 497. Tabel 16 Pengelompokan Skor Shooting.

\begin{tabular}{l|l|l|l} 
No & K t-skore & F absolut & F relatif \\
\hline 1 & BS $\geq 67$ & 0 & $0 \%$ \\
\hline 2 & B 55-66 & 0 & $0 \%$ \\
\hline 3 & S 44-54 & 0 & $0 \%$ \\
\hline 4 & K 32-43 & 1 & $8.3 \%$ \\
\hline
\end{tabular}

\begin{tabular}{l|l|l|l}
\hline 5 & KS $\leq 31$ & 11 & $91.7 \%$ \\
\hline Jumlah & 12 & $100 \%$
\end{tabular}

\section{PENUTUP}

\section{Simpulan}

Berdasarkan hasil penelitian yang telah diuraikan pada bab terdahulu, dapat disimpulkan bahwa hasil yang diperoleh dari kemampuan Passing, Dribbling, dan Shooting SSB u 10-12 tahun di Kabupaten Kaur adalah sebagai berikut,

1. Hasil kemampuan Passing; a. SSB Amura memiliki kemampuan Passing sebanyak 12 pemain (100\%) dalam kategori baik dari 12 testee.; b. SSB Serumpun memiliki kemampuan Passing sebanyak 9 pemain (75\%) dalam kategori baik dan sebanyak 3 pemain(25\%) dalam kategori sedang dari 12 teeste.; c. SSB Persiku memiliki kemampuan Passing sebanyak 9 pemain (75\%) dalam kategori baik, dan 3 pemain (25\%) dalam kategori sedang dari 12 testee. Dari uraian di atas dapat disimpulkan bahwa kemampuan Passing SSB U 10-12 tahun di Kabupaten Kaur dengan sebanyak 36 testee adalah 30 testee $(83,3 \%)$ tergolong kedalam kategori baik, dan 6 testee $(16,7 \%)$ dalam kategori sedang. Sehingga didapatkan kesimpulan bahwa teknik dasar Passing lebih dominan ke dalam kategori baik.

2. Hasil kemampuan Dribbling; a. SSB Amura memiliki kemampuan Dribbling sebanyak 12 pemain (100\%) dalam kategori sedang dari 12 testee.; b, SSB Serumpun sebanyak 8 pemain $(66,67 \%)$ dalam kategori sedang, dan sebanyak 4 pemain (33,37\%) dalam kategori kurang dari 12 testee.; c. SSB Persiku sebanyak 10 pemain $(83,3 \%)$ dalam kategori sedang, dan sebanyak 2 pemain ( $12,7 \%$ ) dalam kategori kurang dari 12 testee. Dari uraian diatas dapat disimpulkan bahwa kemampuan Dribbling SSB U 10-12 tahun di Kabupaten 
Kaur dari 36 testee, sebanyak 30 (83,3\%) dalam kategori sedang, dan 6 teste $(16,7 \%)$ dalam kategori kurang, sehingga didapatkan kesimpulan kemampuan Dribbling yang tergolong kedalam kategori Sedang.

3. Hasil kemampuan Shooting; a. SSB Amura sebanyak 12 pemain (100\%) dalam kategori kurang sekali dari 12 testee.; b. SSB Serumpun sebanyak 1 pemain (8,3\%) dalam kategori kurang dan 11 pemain (91,7 \%) dalam kategori kurang sekali dari 12 testee.; c. SSB Persiku sebanyak 1 pemain (8,3\%) dalam kategori kurang, dan 11 pemain $(91,7 \%)$ termasuk kedalam kategori kurang sekali. Dari keterangan diatas dapat disimpulkan bahwa kemampuan Shooting SSB U 10-12 tahun di Kabupaten Kaur dari 36 testee, sebanyak 2 testee $(5,6 \%)$ dalam kategori kurang, dan 34 testee $(94,4 \%)$ dalam kategori kurang sekali, sehingga didapatkan kesimpulan kemampuan Shooting tergolong kedalam kategori kurang sekali dan masih sangat perlu ditingkatkan lagi

\section{Saran-saran}

Berdasarkan kesimpulan diatas, maka peneliti dapat memberikan beberapa saran yang dapat membantu dalam mengatasi masalah yang ditemui dalam melaksanakan kegiatan latihan sepak bola yang berhubungan dengan teknik dasar Passing, Dribbling, dan Shooting untuk meningkatkan kemampuan para pemain sepak bola masa muda yang akan datang.

1. Kepada Pelatih disarankan untuk lebih memperhatikan dan berupaya meningkatkan lagi sistem latihantentang bagaimana cara melakukan teknik Passing, Dribbling dan Shooting yang lebih baik.
2. Kepada Atlit atau pemain supaya dapat lebih memperhatikan lagi dalam melakukan latihan teknik Passing, Dribbling, dan Shooting dalam permainan sepak bola yang baik dan benar. Pemain juga dituntut untuk memahami teknik dasar permainan sepak bola, dan memiliki satu tujuan yang bulat untuk mampu menguasai teknik dasar sepak bola.

3. Perlu adanya latihan khusus untuk mampu lebih fokusdalam menguasai cara melakukan teknik Passing, Dribbling, dan Shooting yang baik dan sempurna, sehingga dapat diterapkan dalam permainan yang baik dan sempurna.

4. Bagi peneliti lain disarankan untuk dapat mengkaji faktor-faktor lain yang berhubungan dengan Passing, Dribbling, dan Shooting.

Dari uraian diatas dapat disimpulkan bahwa pemain SSB $U$ 10-12 tahun di Kabupaten Kaur masih perlu ditingkatkan lagi sistem pelatihan mengenai teknik dasar sepakbola, karna semakin sempurna teknik dasar seseorang, maka akan lebih muda baginya untuk mengatasi persoalan yang ia hadapi dilapangan. Dan akan lebih baik lagi bila seorang yang memliki kemampuan yang baik mampu mengangkat timnya dalam suatu pertandingan. Namun pada SSB U 10-12 tahun di Kabupaten Kaur masih perlu bimbingan atau pelatihan lagi dalam penguasaan teknik dasar Passing dan Dribbling, terutama Shooting yang tergolong dalam kategori kurang sekali.

\section{DAFTAR PUSTAKA}

Akbar, Andra 2013. Permainan

Sepak Bola di http : //ndraakbar.blogspot.com permainansepakbola.html (akses 2 maret 2019, jam 13.00 WIB). 
Arsil, 2010. Evaluasi Pendidikan

Jasmani dan Olahraga, Malang:

Winika Pedia

Batty, Eric C 1991. Latihan sepak

bola metode baru. Jakarta

Koger, Robert (2007). Latihan Andal

Sepak Bola Remaja. Klaten: Saka mitra kopetesi.Deny

Leo, Arwin, dan Syafrial. 2017. "Profil

Kondisi Fisik Pemain Sepak Bola SMA Negeri 1 Kaur" Jurnal Kinestetik, Vol. 1 (1).

Luxbacher (1996). Sepak Bola langkah langkah menuju sukses. Jakarta:PT GajaGrafindo Persada.

Mielke, D. (2007) Dasar-dasar Sepak

Bola. Bandung: PT Pakar raya

Novriansyah A. 2017. Analisis

kondisi Fisik Dan Keterampilan

Teknik Shooting Pemain Sepak Bola

PS Andeskal Muda. Bengkulu:

Universitas Bengkulu

Sjafri, Indra. (2017), Panduan

Kepelatihan Sepak Bola Anak.

Jakarta: Erlangga Group

Subardi dkk, (2007). Olahraga

kegemaranku sepak bola.

Indonesia:PT Intan Pariwara

Sukatamsi, (2005). Permainan besar

1 sepak bola.Jakarta: unversitas

terbuka

Wijoyo, Giri Y. S dkk (2005)

Manusia dan Olahraga. Bandung:

ITB 